\title{
CONSÓRCIO E SUCESSÃO DE MILHO E FEIJÃO-DE-PORCO COMO ALTERNATIVA DE CULTIVO SOB PLANTIO DIRETO ${ }^{1}$
}

\author{
Leonardo Santos Collier ${ }^{2}$, Fábio Yoshyiuki Kikuchi ${ }^{3}$, Luiz Paulo Figueredo Benício ${ }^{4}$, Sérgio Alves de Sousa ${ }^{4}$
}

\section{ABSTRACT \\ MAIZE AND JACK BEANS INTERCROPPING AND SUCESSION AS ALTERNATIVE FOR NO-TILL SYSTEM}

The use of leguminous species under no-till system can increase the $\mathrm{N}$ content, decreasing the use of nitrogenous fertilizers. However, in ecosystems such as the Brazilian Savannah, the fast decomposition of their straw can result in a deficient soil cover, which can be avoided by intercropping them with a gramineous plant, such as maize. This study aimed to evaluate maize yield; macronutrients contents, with jack beans (Canavalia ensiformis) as green fertilizer and intercropped under no-till system; and rates of crop residues decomposition. The experimental design was split-plot randomized blocks, with four replications, and treatments evaluated per plot were: jack beans sown in October, followed by maize, in December; jack beans sown with maize, in December; maize sown in December, without jack beans, under rice straw; and maize without previous straw, under infesting plants residues dried up at the moment of planting. For split-plots, two $\mathrm{N}$ mineral doses were used $\left(75 \mathrm{~kg} \mathrm{ha}^{-1}\right.$ and $\left.150 \mathrm{~kg} \mathrm{ha}^{-1}\right)$, and, outside delineation, an additional treatment with single jack beans was applied. Treatments with leguminous species did not present significant effect on maize yield and macronutrients content, but there was higher efficiency index per area, with no competitive effect on maize yield. There was no difference among the $\mathrm{N}$ doses, allowing nitrogenous fertilizing reduction. Jack beans, as cover crop or intercropped with maize, did not affect macronutrients composition on the aerial part of leguminous species.

KEY-WORDS: Zea mays L.; Canavalia ensiformis; green fertilizing.

\section{INTRODUÇÃO}

A cultura do milho é responsável pela produção de mais de 50 milhões de toneladas de grãos, apresentando o crescimento mais significativo da safra 2006/2007 (Conab 2007). Esta é a principal cultura utilizada em rotação/sucessão com a soja,

\section{RESUMO}

$\mathrm{O}$ uso de leguminosas em sistema plantio direto (SPD) aumenta o aporte de N, podendo reduzir a necessidade de utilização de fertilizantes nitrogenados. No entanto, em ecossistemas como o Cerrado, a rápida decomposição da palha de leguminosas pode resultar em cobertura deficiente do solo, o que pode ser evitado pelo consórcio da leguminosa com uma gramínea, como o milho. Objetivou-se avaliar a produtividade do milho; teores de macronutrientes, na presença de feijão-deporco (Canavalia ensiformis), como adubo verde e consorciado em SPD; e taxas de decomposição dos resíduos das culturas. O delineamento empregado foi o de blocos casualizados, em parcelas subdivididas, com quatro repetições. Os tratamentos avaliados nas parcelas foram: feijão-de-porco plantado em outubro, seguido por milho, em dezembro; feijão-de-porco plantado junto com milho, em dezembro; milho plantado em dezembro, sem feijão-de-porco, sob palha de arroz; e milho sem palhada antecessora, sob resíduos de plantas infestantes, dessecadas no momento do plantio. Nas subparcelas, foram alocadas duas doses de $\mathrm{N}$ mineral $\left(75 \mathrm{~kg} \mathrm{ha}^{-1}\right.$ e $150 \mathrm{~kg} \mathrm{ha}^{-1}$ ) e, fora do delineamento, um tratamento adicional com feijão-de-porco solteiro. Os tratamentos com a leguminosa não apresentaram efeito significativo na produtividade de milho e teor de macronutrientes, mas, nestes tratamentos, houve maior índice de eficiência por área, sem efeito competitivo na produção do milho. Não houve diferença entre as doses de N, possibilitando redução da adubação nitrogenada. O feijão-deporco, como cobertura ou consorciado, não afetou a composição de macronutrientes, na parte aérea da leguminosa.

PALAVRAS-CHAVES: Zea mays L.; Canavalia ensiformis; adubação verde.

destacando-se em área cultivada e produção, nas regiões Centro-Oeste, Sul e Sudeste, e com expressiva área no bioma Cerrado.

O sistema plantio direto (SPD) tem se destacado como alternativa importante para a produção de grãos, devido à melhoria na qualidade do solo, associada à ciclagem de nutrientes, aumento da ativi-

1. Trabalho recebido em jan./2010 e aceito para publicação em jul./2011 (nº registro: PAT 8706/ DOI: 10.5216/pat.v41i3.8706). 2. Universidade Federal de Goiás, Escola de Agronomia e Engenharia de Alimentos, Goiânia, GO, Brasil.E-mail: collierufg@gmail.com. 3. G9 Agronegócios, Campo Alegre de Goiás, GO, Brasil.E-mail: fykikuchi@gmail.com.

4. Universidade Federal do Tocantins, Gurupi, TO, Brasil.E-mails: luizpaulo.figueredo@gmail.com, sergioalves_sousa@hotmail.com. 
dade biológica e adição de resíduos culturais ao solo, reduzindo, assim, o risco de impactos ambientais ocasionados pelo uso intensivo do solo. A manutenção de palha na superfície e o cultivo em solo sem revolvimento resultam em maior aporte de matéria orgânica e nutrientes no sistema, podendo interferir na eficiência da adubação mineral dos cultivos (Sá 1996, Bernardi et al. 2003, Collier et al. 2008).

Apesar dos benefícios associados ao SPD, a adoção deste sistema, em algumas regiões como o Tocantins, é dificultada, devido ao fato de a concentração do período chuvoso e as elevadas temperaturas da região favorecerem a rápida decomposição de resíduos, tornando difícil a manutenção de palhada sobre o solo, nestas regiões (Silva et al. 2003).

Além do clima e de outros fatores, deve ser considerada a relação $\mathrm{C} / \mathrm{N}$ das plantas de cobertura, na predição das taxas de decomposição dos resíduos vegetais. Resíduos com alta relação $\mathrm{C} / \mathrm{N}$ favorecem a manutenção da palha sobre o solo, mas podem resultar em menor disponibilidade de $\mathrm{N}$ à cultura em sucessão. Na maioria das culturas, como é o caso do milho, o nitrogênio é o elemento exigido em maiores quantidades, sendo o que mais frequentemente limita o rendimento de grãos (Bortolini et al. 2002).

Amado et al. (2002) demonstraram a importância de se considerar a cultura antecessora ao milho, para o manejo de N no SPD. Segundo Sá (1996), a utilização de leguminosa na rotação, antecedendo o milho, proporcionou economia de $50 \%$ de nitrogênio. Elevadas respostas na produtividade dos cultivos subsequentes (Duarte Júnior \& Coelho 2008), com maiores valores de biomassa e reciclagem de nutrientes, foram obtidos com a Crotalaria juncea (Carvalho et al. 2004, Fontanetti et al. 2006), guandu e feijão-de-porco (Collier et al. 2008). Fosu et al. (2004) obtiveram incrementos de duas a quatro vezes, na produção de milho sob resíduos de leguminosas, em região de savana, em Gana.

Uma alternativa para se reduzir as taxas de decomposição de leguminosas e evitar que ocorram altas taxas de imobilização do $\mathrm{N}$ no solo é o cultivo consorciado. $\mathrm{O}$ consórcio entre gramíneas e leguminosas apresenta, como vantagens, o maior rendimento de matéria seca, em relação ao cultivo isolado de cada espécie; maior estímulo na fixação biológica de N2, pela leguminosa; e maior eficiência na utilização da água e dos nutrientes do solo, devido à exploração de diferentes volumes de solo por sistemas radiculares com padrões distintos. Dentre as espécies apropriadas ao consórcio com o milho, Calegari (1995) recomenda o feijão-de-porco e a mucuna-preta. Heinrichs et al. (2005) evidenciaram que o feijão-de-porco, em comparação com mucuna anã, guandu anão, crotalária e plantas infestantes, proporcionou maior produção de fitomassa e acúmulo de $\mathrm{N}, \mathrm{P}, \mathrm{K}, \mathrm{Ca}, \mathrm{Mg}$ e S, e, ainda, maiores rendimentos, quando consorciado com o milho, em relação aos demais adubos verdes. Silva et al. (2002) destacam o uso de crotalaria, guandu e lab-lab, com incrementos nos níveis de $\mathrm{Ca}, \mathrm{N}, \mathrm{K}$ e $\mathrm{P}$, quando cultivados e manejados nas entrelinhas de laranjeiras. Em trabalho de Ezeibekwe \& Anyaegbu (2004), mais de 200\% de incremento foram obtidos nos cultivos de milho consorciado com caupi, em relação ao cultivo solteiro, em solos arenosos da Nigéria.

Porém, no cultivo consorciado, as espécies, normalmente, diferem em altura e em distribuição das folhas no espaço, dentre outras características morfológicas, que podem levar as plantas a competir por energia luminosa, água e nutrientes (Maciel et al. 2004). Segundo Oliveira et al. (2002), em milho, os melhores resultados de massa de 100 grãos foram obtidos pelas plantas cultivadas sob palhadas do feijão-de-porco, podendo-se atribuir tal resultado ao fato de a leguminosa ter disponibilizado o $\mathrm{N}$ em menor tempo que as demais plantas de cobertura, em razão da rápida decomposição. De acordo com Resende et al. (2000), 60 dias é o prazo necessário para que ocorra a mineralização da metade do $\mathrm{N}$ contido na parte aérea do feijão-de-porco. Assim, é provável que a disponibilização mais rápida do $\mathrm{N}$, coincidindo com o período de maior exigência pela cultura, possa melhorar a produtividade. Cabe ressaltar, no entanto, que Collier et al. (2006) obtiveram maiores produtividades de milho sob resíduos de crotalária, quando comparado ao feijão-de-porco.

Neste contexto, objetivou-se, com este traba1ho, avaliar a produtividade e o acúmulo de macronutrientes, em milho (Zea mays) cultivado em sistema plantio direto consorciado com feijão-de-porco (Canavalia ensiformis) ou com o uso da leguminosa como adubo verde associado a duas doses de N.

\section{MATERIAL E MÉTODOS}

O experimento foi desenvolvido durante a safra 2007/2008, na estação experimental da Universidade Federal do Tocantins (UFT), Campus Universitário de Gurupi (11 ${ }^{\circ} 43^{\prime} \mathrm{S}, 4^{\circ} 04^{\prime} \mathrm{N}$ e $280 \mathrm{~m}$ de altitude), em 
Latossolo Vermelho-Amarelo distrófico típico, com $282 \mathrm{~g} \mathrm{~kg}^{-1}$ de argila. O local de instalação do experimento foi uma área onde se desenvolve plantio direto com rotação de culturas e plantas de cobertura, desde 2000, na qual se cultivou arroz, na safra anterior.

O delineamento empregado foi o de blocos ao acaso, em parcelas subdivididas, com quatro repetições. Os tratamentos avaliados nas parcelas foram: 1) feijão-de-porco (FP) semeado em outubro, seguido de milho (M), em dezembro (M sob FP); 2) feijão-de-porco semeado junto com milho, em dezembro (M com FP); 3) milho semeado em dezembro, sem feijão-de-porco e com palha de arroz (M sem FP); 4) milho sem palhada antecessora, sob os resíduos das plantas infestantes, dessecadas no momento do plantio (M s/ palhada). Nas subparcelas, foram alocadas duas doses de $\mathrm{N}$ mineral $\left(75 \mathrm{~kg} \mathrm{ha}^{-1} \mathrm{e}\right.$ $\left.150 \mathrm{~kg} \mathrm{ha}^{-1}\right) \mathrm{e}$, fora do delineamento, um tratamento adicional com feijão-de-porco solteiro (FP solteiro), totalizando 48 unidades experimentais e seis unidades com tratamento de feijão-de-porco solteiro. As unidades experimentais foram compostas por seis linhas de milho, de 5,0 $\mathrm{m}$ de comprimento, espaçadas em $0,45 \mathrm{~m}$, totalizando $11,25 \mathrm{~m}^{2}$ cada. O milho foi semeado com 5 plantas por metro linear, atingindo estande de 111.000 plantas por hectare.

No tratamento 1 , o feijão-de-porco foi semeado em 22 de outubro e, quando iniciou-se o florescimento, amostras foliares foram coletadas, para determinação da extração de macronutrientes, pela cultura. A dessecação da leguminosa foi realizada 50 dias após a semeadura (DAS), com o herbicida glyphosate. Na dessecação, foi utilizada a fórmula comercial Roundup, na dose de 1,5 $\mathrm{L} \mathrm{ha}^{-1}$. A produção de matéria seca do feijão-de-porco, para o tratamento controle, foi quantificada coletando-se todo o material vegetal rente ao solo, em cinco locais de $0,25 \mathrm{~m}^{2}$, com lançamento de quadrado metálico $(0,5 \mathrm{~m} \times 0,5 \mathrm{~m})$ na área, de forma aleatória. A massa de matéria fresca foi determinada e, em seguida, para determinação da massa de matéria seca, subamostras foram retiradas e acondicionadas em estufa, por 72 horas, a $65^{\circ} \mathrm{C}$, até massa constante.

Antes do plantio do milho, amostras de solo das áreas com e sem feijão-de-porco foram coletadas, para caracterização química do solo, realizada no Laboratório de Química do Solo da UFT, segundo metodologia da Embrapa (1997), com exceção do carbono orgânico, que foi determinado pelo método de Walkley-Black (1934).
Aos 10 dias após a dessecação das plantas de cobertura (21 de dezembro), o milho precoce (cultivar AGN 30A06) foi semeado com adubação de $125 \mathrm{~kg} \mathrm{ha}^{-1}$ de $\mathrm{P}$ e $75 \mathrm{~kg} \mathrm{ha}^{-1}$ de $\mathrm{K}$, realizada no início da instalação do experimento. A adubação nitrogenada foi parcelada em 1/3 no plantio e $2 / 3 \mathrm{em}$ cobertura, aos 35 dias após a semeadura, utilizando-se ureia nas duas aplicações.

Para determinação da extração de nutrientes pelo milho, foram coletadas amostras foliares, na época do surgimento da inflorescência feminina (cabelo). A colheita do milho foi realizada na segunda quinzena de abril, sendo colhidas espigas das quatro fileiras centrais, para determinação da massa de grãos. A massa de matéria seca da parte aérea do milho foi determinada conforme metodologia descrita para massa de matéria seca do feijão-de-porco.

Para avaliar o efeito da palha sobre os atributos químicos do solo, foram realizadas amostragens de solo, na camada $0-0,20$ m, após a dessecação do feijão-de-porco, no tratamento 1 , e após a colheita do milho, nos demais tratamentos.

Os resultados de produção de grãos, matéria seca, massa de espiga e atributos químicos da fertilidade do solo foram submetidos a análise de variância, utilizando-se o software ASSISTAT (Silva \& Azevedo 2006) e empregando-se o teste Tukey, para comparação de médias.

\section{RESULTADOS E DISCUSSÃO}

\section{Atributos químicos do solo}

Os atributos químicos do solo (Tabela 1), no início da implantação do experimento, não diferiram entre os tratamentos com e sem feijão-de-porco, antes do plantio do milho, ao contrário do observado por Heinrichs et al. (2005), que constataram acúmulo de N, P, K, Ca, Mg e S, comparando-se o feijão-de-porco com outras leguminosas. De maneira geral, o cultivo do feijão-de-porco, no período, não comprometeu o padrão de fertilidade do solo, devido ao crescimento de sua biomassa.

Após a colheita do milho, a acidez potencial e o $\mathrm{pH}$ do solo diferiram entre os tratamentos com e sem palha de feijão-de-porco, evidenciando que a leguminosa reduz a acidez do solo (Tabela 2). Esta diferença salientou a capacidade que o feijão-de-porco tem em amenizar os efeitos da acidez, visto que o aumento do $\mathrm{pH}$ e a redução da acidez potencial 
Tabela 1. Atributos químicos do solo, na camada 0-0,20 m, dos tratamentos com e sem feijão-de-porco, antes do plantio do milho (Gurupi, TO, 2007).

\begin{tabular}{|c|c|c|c|c|c|c|c|c|}
\hline \multirow{2}{*}{ Tratamento } & $\mathrm{Ca}$ & $\mathrm{Mg}$ & $\mathrm{Al}$ & $\mathrm{H}+\mathrm{Al}$ & $\mathrm{K}$ & $\mathrm{P}$ & \multirow{2}{*}{$\begin{array}{c}\mathrm{pH} \\
\mathrm{CaCl}_{2}\end{array}$} & M.O. \\
\hline & \multicolumn{4}{|c|}{$\mathrm{mmol}_{\mathrm{c}} \mathrm{dm}^{-3}$} & \multicolumn{2}{|c|}{$\mathrm{mg} \mathrm{dm}^{-3}$} & & $\mathrm{~g} \mathrm{dm}^{-3}$ \\
\hline Sem feijão-de-porco & 24,74 & 4,42 & 1,30 & 29,24 & 65,52 & 13,72 & 5,34 & 25,84 \\
\hline Com feijão-de-porco & 28,50 & 3,74 & 1,50 & 29,00 & 52,26 & 11,02 & 5,46 & 26,34 \\
\hline
\end{tabular}

Dados não significativos, pelo teste t, a $5 \%$.

Tabela 2. Atributos químicos do solo, na camada 0-0,2 m, após a colheita do milho, sob diferentes tratamentos e doses de nitrogênio (Gurupi, TO, 2008).

\begin{tabular}{|c|c|c|c|c|c|c|c|}
\hline \multirow{2}{*}{ Tratamento } & $\mathrm{Ca}$ & $\mathrm{Mg}$ & $\mathrm{H}+\mathrm{Al}$ & $\mathrm{K}$ & $\mathrm{P}$ & \multirow{2}{*}{$\begin{array}{c}\mathrm{pH} \\
\mathrm{CaCl}_{2}\end{array}$} & \multirow{2}{*}{$\frac{\text { M.O. }}{\mathrm{g} \mathrm{dm}^{-3}}$} \\
\hline & \multicolumn{3}{|c|}{$\mathrm{mmol}_{\mathrm{c}} \mathrm{dm}^{-3}$} & \multicolumn{2}{|c|}{$\mathrm{mg} \mathrm{dm}^{-3}$} & & \\
\hline M sob FP & $45,17 \mathrm{a}$ & $10,83 \mathrm{a}$ & $41,17 \mathrm{ab}$ & $95,02 \mathrm{a}$ & $0,31 \mathrm{a}$ & $5,45 \mathrm{ab}$ & $32,56 \mathrm{a}$ \\
\hline M com FP & $38,17 \mathrm{a}$ & $9,05 \mathrm{a}$ & $47,33 \mathrm{ab}$ & $93,14 \mathrm{a}$ & $0,35 \mathrm{a}$ & $5,53 \mathrm{ab}$ & $32,22 \mathrm{a}$ \\
\hline M sem FP & $41,67 \mathrm{a}$ & $11,50 \mathrm{a}$ & 50,16 a & $99,57 \mathrm{a}$ & $0,13 \mathrm{a}$ & $5,27 \mathrm{~b}$ & $33,29 \mathrm{a}$ \\
\hline FP solteiro & $43,33 \mathrm{a}$ & $11,33 \mathrm{a}$ & $41,00 \mathrm{~b}$ & $94,60 \mathrm{a}$ & $0,20 \mathrm{a}$ & $5,60 \mathrm{a}$ & $27,05 \mathrm{a}$ \\
\hline Milho s/ palhada & $45,00 \mathrm{a}$ & $8,67 \mathrm{a}$ & $46,00 \mathrm{ab}$ & $89,01 \mathrm{a}$ & $0,43 \mathrm{a}$ & $5,58 \mathrm{a}$ & $33,26 \mathrm{a}$ \\
\hline C.V. $(\%)$ & 16,17 & 25,34 & 10,51 & 31,93 & 75,63 & 2,99 & 14,16 \\
\hline $75 \mathrm{~kg} \mathrm{ha}^{-1}$ de $\mathrm{N}$ & $43,20 \mathrm{a}$ & $10,27 \mathrm{a}$ & $44,67 \mathrm{a}$ & $91,65 \mathrm{a}$ & $0,27 \mathrm{a}$ & $5,50 \mathrm{a}$ & $32,51 \mathrm{a}$ \\
\hline $150 \mathrm{~kg} \mathrm{ha}^{-1}$ de N & $42,13 \mathrm{a}$ & $10,47 \mathrm{a}$ & $45,60 \mathrm{a}$ & $96,89 \mathrm{a}$ & $0,30 \mathrm{a}$ & $5,47 \mathrm{a}$ & $30,84 \mathrm{a}$ \\
\hline C.V. $(\%)$ & 11,46 & 14,84 & 9,98 & 19,30 & 84,25 & 3,03 & 10,66 \\
\hline
\end{tabular}

M sob FP: milho semeado sob palhada de feijão-de-porco; M com FP: milho consorciado com feijão-de-porco; M sem FP: milho semeado sem palhada de feijão-de-porco;

M s/ palhada: milho semeado sem palhada de cobertura antecessora. Médias seguidas de mesma letra não diferem, estatisticamente, entra si, a $5 \%$, pelo teste Tukey.

somente foram verificados nos tratamentos onde a leguminosa foi empregada. O tratamento $\mathrm{M}$ sem $\mathrm{FP}$, que obteve as maiores produtividades, gerou consequências na fertilidade do solo, promovendo maior acidificação e aumento no teor de $\mathrm{H}+\mathrm{Al}$, em relação ao uso isolado do FP (Tabela 2). O tratamento com acréscimo de palhada não diferiu dos demais, evidenciando que a falta de resíduo, nesta safra, após sete ciclos sucessivos de formação de coberturas na área, não reduziu a fertilidade do solo.

Analisando-se os valores de produtividade e fertilidade do solo, é possível concluir que, em sistema plantio direto, a resposta a diferentes tratamentos é lenta, permanecendo influências da cultura e palhada antecessoras. A análise dos valores, antes e após o plantio do milho (Tabelas 1 e 2), indica incremento no teor de $\mathrm{Ca}, \mathrm{Mg}, \mathrm{H}+\mathrm{Al}, \mathrm{K}$ e matéria orgânica (M.O.), em todos os tratamentos, devido, possivelmente, ao aporte destes nutrientes, após a decomposição da palhada antecessora.

Trabalhando com o cultivo de crotalária e feijão-de-porco, nas entrelinhas de videiras, Faria et al. (2004) somente obtiveram incrementos na camada mais superficial do solo e nos níveis de $\mathrm{Ca}, \mathrm{CTC}$ e M.O., o que pode estar relacionado com a redução de acidez obtida no trabalho em questão. Embora não tenha sido cultivado milho no tratamento feijão-de-porco solteiro, verifica-se redução nos níveis de matéria orgânica do solo sobre o efeito priming de se ativar a biota do solo, na decomposição da matéria orgânica já existente, concordando com Gama-Rodrigues et al. (2007). Percebe-se a contribuição da palhada de arroz (no início) e milho, para manutenção do carbono no solo.

$\mathrm{O}$ aumento expressivo dos níveis de $\mathrm{K}$ pode ser decorrente da adubação, mas, também, pode estar relacionado à liberação mais rápida deste elemento pelos resíduos, conforme observado por Gama-Rodrigues et al. (2007). O P se destaca pelo decréscimo muito acentuado dos seus níveis.

Teores foliares de nutrientes na matéria seca do feijão-de-porco e do milho

Os teores foliares dos nutrientes $\mathrm{N}, \mathrm{P}, \mathrm{K}, \mathrm{Mg}$ e $\mathrm{S}$, na matéria seca de milho (Tabela 3 ), não diferiram entre os tratamentos. Trabalhos quantificaram alta velocidade de decomposição de resíduos, mesmo em períodos de baixa intensidade pluviométrica (Silva et al. 2003), o que sugere que a concentração do período 
Tabela 3. Teores foliares de macronutrientes das amostras de milho, sob os diferentes tratamentos (Gurupi, TO, safra 2007/2008).

\begin{tabular}{|c|c|c|c|c|c|c|}
\hline \multirow{2}{*}{ Tratamento } & $\mathrm{N}$ & $\mathrm{P}$ & K & $\mathrm{Ca}$ & $\mathrm{Mg}$ & $\mathrm{S}$ \\
\hline & \multicolumn{6}{|c|}{$\longrightarrow \mathrm{g} \mathrm{kg}^{-1}$} \\
\hline Milho sob FP & $21,86 \mathrm{a}$ & $5,14 \mathrm{a}$ & $30,12 \mathrm{a}$ & $3,79 \mathrm{a}$ & $3,42 \mathrm{a}$ & $2,84 \mathrm{a}$ \\
\hline Milho com FP & $18,84 \mathrm{a}$ & $4,68 \mathrm{a}$ & 29,19 a & $3,81 \mathrm{a}$ & $3,38 \mathrm{a}$ & $2,67 \mathrm{a}$ \\
\hline Milho sem FP & $20,67 \mathrm{a}$ & $4,69 \mathrm{a}$ & 29,77 a & 3,77 a & $2,97 \mathrm{a}$ & $2,68 \mathrm{a}$ \\
\hline Milho s/ palhada & $19,91 \mathrm{a}$ & $4,66 \mathrm{a}$ & $28,69 \mathrm{a}$ & $3,65 \mathrm{a}$ & $3,03 \mathrm{a}$ & $2,61 \mathrm{a}$ \\
\hline C.V. $(\%)$ & 25,21 & 14,08 & 9,78 & 15,15 & 16,68 & 11,59 \\
\hline $75 \mathrm{~kg} \mathrm{ha}^{-1}$ de $\mathrm{N}$ & $19,63 \mathrm{a}$ & $4,65 \mathrm{a}$ & $29,20 \mathrm{a}$ & $3,77 \mathrm{a}$ & $3,15 \mathrm{a}$ & $2,64 b$ \\
\hline $150 \mathrm{~kg} \mathrm{ha}^{-1}$ de $\mathrm{N}$ & $20,59 \mathrm{a}$ & $4,91 \mathrm{a}$ & $29,68 \mathrm{a}$ & $3,74 \mathrm{a}$ & $3,25 \mathrm{a}$ & $2,77 \mathrm{a}$ \\
\hline C.V. $(\%)$ & 17,75 & 9,35 & 5,55 & 11,94 & 10,00 & 5,65 \\
\hline
\end{tabular}

M sob FP: milho semeado sob palhada de feijão-de-porco; M com FP: milho consorciado com feijão-de-porco; M sem FP: milho semeado sem palhada de feijão-de-porco;

M s/ palhada: milho semeado sem palhada de cobertura antecessora. Médias seguidas de mesma letra não diferem, estatisticamente, entre si, a $5 \%$, pelo teste Tukey.

Tabela 4. Teores foliares de amostras de feijão-de-porco, sob diferentes tratamentos (Gurupi, TO, 2007).

\begin{tabular}{|c|c|c|c|c|c|c|}
\hline \multirow{2}{*}{ Tratamento } & $\mathrm{N}$ & $\mathrm{P}$ & $\mathrm{K}$ & $\mathrm{Ca}$ & $\mathrm{Mg}$ & $\mathrm{S}$ \\
\hline & \multicolumn{6}{|c|}{$-\mathrm{g} \mathrm{kg}^{-1}$} \\
\hline Feijão-de-porco consorciado & $48,00 \mathrm{a}$ & $3,66 \mathrm{~b}$ & $25,33 \mathrm{a}$ & $23,12 \mathrm{a}$ & $5,51 \mathrm{a}$ & $3,51 \mathrm{a}$ \\
\hline Feijão-de-porco solteiro & $50,08 \mathrm{a}$ & $4,25 \mathrm{a}$ & $24,71 \mathrm{a}$ & $20,31 \mathrm{~b}$ & $5,04 \mathrm{~b}$ & $3,23 \mathrm{a}$ \\
\hline C.V. $(\%)$ & 9,63 & 5,33 & 4,45 & 12,96 & 9,30 & 11,82 \\
\hline
\end{tabular}

Médias seguidas de mesma letra não diferem, estatisticamente, entra si, a 5\%, pelo teste Tukey.

chuvoso e as altas temperaturas possam influenciar na liberação mais rápida de nutrientes, nas situações obtidas neste trabalho.

Quando foram avaliados os teores foliares de feijão-de-porco (Tabela 4), percebeu-se que as plantas do cultivo consorciado acumularam mais $\mathrm{Ca}$ e $\mathrm{Mg}$, enquanto as plantas do cultivo solteiro absorveram mais fósforo (tabela 4). Mesmo considerando-se a menor produção de biomassa do cultivo consorciado, a competição com o milho pode explicar tais diferenças.

Os teores foliares de $\mathrm{K}, \mathrm{Ca}, \mathrm{Mg}$ e $\mathrm{S}$, no feijão-de-porco consorciado, resultaram da baixa produtividade da parte aérea, possibilitando maior percentagem destes nutrientes, em relação ao cultivo isolado, onde a grande quantidade de massa produzida proporcionou diluição. Em trabalhos com feijão-de-porco, Gama-Rodrigues et al. (2007) e Teixeira et al. (2005) obtiveram teores foliares (com exceção do Ca) abaixo do obtido neste trabalho (Tabelas 4 e 5), explicados pelo uso de solos de menor fertilidade atual e menor adubação, que, neste trabalho, foi superior, tendo o espaçamento empregado para o milho, possivelmente, facilitado a assimilação dos nutrientes. Mesmo que os diferentes resultados obtidos na literatura não permitam discussão comparativa, os valores químicos foliares (Tabelas 4 e 5) demonstram que o feijão-de-porco, se comparado ao milho, nes- tas condições, é eficiente na obtenção de nutrientes, principalmente de $\mathrm{N}, \mathrm{Ca}, \mathrm{Mg}$ e $\mathrm{S}$, qualificando-se como reserva orgânica de nutrientes.

Outro fator que poderia explicar os teores muito próximos de macronutrientes no feijão-de-porco é a ausência de variação da densidade de plantio na linha, pois, segundo Perin et al. (2003), as diferenças nos teores de NPK do amendoim forrageiro foram

Tabela 5. Produtividade de grãos, espiga e massa seca de milho, sob diferentes sistemas de consórcio e doses de nitrogênio (Gurupi, TO, safra 2007/2008).

\begin{tabular}{lccc}
\hline \multirow{2}{*}{ Tratamento } & Massa seca & Espiga & Grãos \\
\cline { 2 - 4 } & \multicolumn{3}{c}{$\mathrm{kg} \mathrm{ha}^{-1}$} \\
\hline M sob FP & $16941,67 \mathrm{a}$ & $6618,33 \mathrm{a}$ & $5820,36 \mathrm{a}$ \\
M com FP & $16725,00 \mathrm{a}$ & $6211,67 \mathrm{a}$ & $5546,85 \mathrm{a}$ \\
M sem FP & $17541,67 \mathrm{a}$ & $6767,50 \mathrm{a}$ & $5974,68 \mathrm{a}$ \\
M s/ palhada & $14383,33 \mathrm{a}$ & $5572,50 \mathrm{a}$ & $4917,96 \mathrm{a}$ \\
\hline C.V. $(\%)$ & 24,96 & 22,11 & 22,10 \\
\hline $75 \mathrm{~kg} \mathrm{ha}^{-1} \mathrm{de} \mathrm{N}$ & $16079,17 \mathrm{a}$ & $6332,08 \mathrm{a}$ & $5611,78 \mathrm{a}$ \\
$150 \mathrm{~kg} \mathrm{ha}^{-1} \mathrm{de} \mathrm{N}$ & $16079,17 \mathrm{a}$ & $6252,92 \mathrm{a}$ & $5518,15 \mathrm{a}$ \\
\hline C.V. $(\%)$ & 16,81 & 13,01 & 13,92 \\
\hline
\end{tabular}

M sob FP: milho semeado sob palhada de feijão-de-porco; M com FP: milho consorciado com feijão-de-porco; M sem FP: milho semeado sem palhada

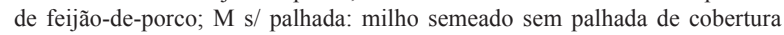
antecessora. Médias seguidas de mesma letra não diferem, estatisticamente, entre si, a $5 \%$, pelo teste Tukey. 
obtidas, principalmente, quando variou-se a densidade de plantas na linha.

Embora se destaque, para discussão, a presença do feijão-de-porco, nos tratamentos onde a leguminosa não esteve presente, e mesmo naqueles em que a cultura foi introduzida junto com o milho, houve, também, presença da palha de arroz em decomposição. Não houve indício de que a palha tenha comprometido a absorção do $\mathrm{N}$ pelo milho (Tabela 4). Resultados semelhantes foram obtidos por Bremer Neto et al. (2008), trabalhando com palha de braquiária, dentre outras plantas, em cultivo de citros.

Quando se aplicam os teores obtidos (Tabelas 3 e 4) na massa seca dos resíduos (Tabela 5), pode-se quantificar os teores de $\mathrm{N}$ contidos nas palhadas de milho e feijão-de-porco, obtendo-se $370,34 \mathrm{~kg} \mathrm{ha}^{-1}$, no tratamento M sob FP, seguido do M sem FP $\left(362,59 \mathrm{~kg} \mathrm{ha}^{-1}\right)$ e do M com FP $\left(362,18 \mathrm{~kg} \mathrm{ha}^{-1}\right)$. Como os valores não foram submetidos a análise estatística, e não houve esta diferenciação nem para os totais de massa seca (Tabela 5) nem para os teores de nutrientes, o tratamento $\mathrm{M}$ sem FP pode ser indicado, devido à menor complexidade de manejo e boa produtividade (Tabela 5). Embora os trabalhos de Duarte Júnior \& Coelho (2008) destaquem os maiores teores de $\mathrm{N}$ na parte aérea de cana-de-açúcar, quando cultivada sob palhada de leguminosas como feijão-de-porco e crotalária, em função dos seus teores nos tecidos, neste trabalho, não houve suporte para esta conclusão.

A contribuição da palha na superfície do solo, resultando no aporte de matéria orgânica e nutrientes e interferindo na eficiência da adubação química dos cultivos subsequentes, foi verificada por Crusciol et al. (2005) e Chagas et al. (2007). Em função destes resultados, acredita-se que o tratamento $\mathrm{M}$ sob FP participou no fornecimento de $\mathrm{N}$ e demais macronutrientes para o milho, interferindo na dinâmica de liberação de $\mathrm{N}$ e outros nutrientes para o solo, com reflexos para os cultivos subsequentes. O menor resultado do teor de $\mathrm{N}$ nos resíduos foi obtido no tratamento M s/ palhada $\left(286,47 \mathrm{~kg} \mathrm{ha}^{-1}\right)$, coincidindo com a menor produtividade de grãos de massa seca, o que evidencia a importância do resíduo vegetal na adoção do SPD.

\section{Produção das culturas de cobertura e do milho}

A produção de massa de matéria seca obtida com o feijão-de-porco, no tratamento 1 (plantio antecipado do feijão-de-porco), foi de $1,5 \mathrm{Mg} \mathrm{ha}^{-1}$, valor, este, inferior aos $6,0 \mathrm{Mg} \mathrm{ha}^{-1}$ citados por Darolt \& Skora Neto (2002), como sendo a quantidade mínima ideal de matéria seca, em sistema de rotação de culturas. Este resultado pode ser atribuído ao curto tempo de desenvolvimento da cultura (50 dias). A quantidade de massa seca, espiga e grãos de milho produzidos por hectare não diferiram entre os tratamentos (Tabela 5), sugerindo ausência de competição do feijão-de-porco com o milho, com reflexos na produção. $\mathrm{O}$ menor resultado numérico foi obtido no tratamento $\mathrm{M} \mathrm{s}$ / palhada. A ausência de competição também foi concluída por Perin et al. (2007), trabalhando em Viçosa (MG), mesmo com plantio na linha.

A produtividade de massa de matéria seca do feijão-de-porco solteiro e consorciado do tratamento M com FP foi de $6.638,83 \mathrm{~kg} \mathrm{ha}^{-1}$ e $980,83 \mathrm{~kg} \mathrm{ha}^{-1}$, respectivamente, sugerindo a presença de efeito competitivo para a leguminosa. Porém, a análise desta produtividade, a partir do IEA, indicou resultados positivos, onde a produtividade do consórcio de milho e feijão-de-porco foi $36 \%$ superior à dos seus cultivos isolados, permitindo concluir que o milho consorciado e o feijão-de-porco consorciado, mesmo atingindo menores produtividades de matéria seca, foram capazes de superar, em conjunto, todos os tratamentos isolados.

A diferença bastante expressiva entre a produção de biomassa seca do feijão-de-porco solteiro e consorciado se deve ao espaçamento adotado, o que se confirma com o estudo de Perin et al. (2007), trabalhando com milho e feijão-de-porco na linha, a cada 1,0 m. Embora não tenha ocorrido acréscimo na produtividade, como observado por Castro et al. (2005), utilizando leguminosas intercaladas com berinjela, ficou evidente que a competição entre as culturas não reduziu a produtividade da cultura principal.

A produção do milho não foi alterada pela dose de $\mathrm{N}$ aplicada (Tabela 5), sendo recomendada a utilização da menor dose, o que representou economia de 50\% de fertilizantes, para a cultura do milho. Como não houve interação da dose de $\mathrm{N}$ com os sistemas de cultivo, quanto à presença do feijão-de-porco, não foi possível atribuir a economia de $\mathrm{N}$ à presença dos resíduos da leguminosa. O tratamento com a remoção da palhada anterior reduziu, em média, $15 \%$ e $16 \%$ a produção de grãos e massa seca de resíduos, respectivamente.

A produção de biomassa do feijão-de-porco foi inferior ao potencial da cultura na região (Collier et 
al. 2006). O curto tempo de cultivo, no tratamento iniciado em outubro, e a competição exercida pelo milho, nos demais tratamentos, explicam a baixa produção de biomassa, refletindo nos resultados obtidos.

\section{CONCLUSÕES}

1. O milho cultivado em área com mais de 6 anos de establecimento de plantio direto não sofreu efeito do consórcio com o feijão-de-porco, em seus parâmetro produtivos, nas condições do trabalho.

2. Não houve necessidade de se trabalhar com altos níveis de adubação nitrogenada para o milho, nos sistemas estudados sob o histórico de plantio direto, proporcionando economia do uso de fertilizantes, para a cultura.

3. Embora a planta de feijão-de-porco tenha diferenças entre sua demanda de macronutrientes, quando consorciada, um único ciclo de cultivo da leguminosa, antecedendo o milho ou consorciado com o mesmo, não foi capaz de promover alterações expressivas nos atributos químicos da fertilidade do solo e nos teores de macronutrientes foliares nas plantas de milho, nas condições do experimento, $\mathrm{o}$ que não significa que este sistema de cultivo não seja recomendável para a manutenção do sistema plantio direto, considerando-se o milho como cultura principal.

\section{REFERÊNCIAS}

AMADO, T. J. C.; MIELNICZUK, J.; AITA, C. Recomendação de adubação nitrogenada para o milho no RS e SC adaptado para o uso de culturas de cobertura do solo sob SPD. Revista Brasileira de Ciência do Solo, Viçosa, v. 26, n. 2, p. 241-248, 2002.

BERNARDI, A. C. C. et al. Correção do solo e adubação no sistema plantio direto nos cerrados. Rio de Janeiro: Embrapa Solos, 2003. (Documentos, 46).

BORTOLINI, C. G. et al. Sistemas de aplicação de nitrogênio e seus efeitos sobre o acúmulo de $\mathrm{N}$ na planta de milho. Revista Brasileira de Ciência do Solo, Viçosa, v. 26, n. 3, p. 361-366, 2002.

BREMER NETO, H. et al. Estado nutricional e produção de laranjeira 'Pêra' em função da vegetação intercalar e da cobertura morta. Pesquisa Agropecuária Brasileira, Brasília, DF, v. 43, n. 1, p. 29-35, 2008.

CALEGARI, A. Leguminosas para adubação verde de verão no Paraná. Londrina: IAPar, 1995. (Circular, 80).
CARVAlHO, M. A. C. de et al. Produtividade do milho em sucessão a adubos verdes no sistema de plantio direto e convencional. Pesquisa Agropecuária Brasileira, Brasília, DF, v. 39, n. 1, p. 47-53, 2004.

CASTRO, C. M. et al. Plantio direto, adubação verde e suplementação com esterco de aves na produção orgânica de berinjela. Pesquisa Agropecuária Brasileira, Brasília, DF, v. 40, n. 5, p. 495-502, 2005.

CHAGAS, E. et al. Decomposição e liberação de nitrogênio, fósforo e potássio de resíduos da cultura do feijoeiro. Revista Brasileira de Ciência do Solo, Viçosa, v. 31, n. 2, p. 723-729, 2007.

COLLIER, L. S. et al. Adubação fosfatada no sulco e em faixa sob palhada de leguminosa e produtividade do milho em plantio direto no Tocantins. Revista Ceres, Viçosa, v. 55, n. 2, p. 109-116, 2008.

COLLIER, L. S. et al. Manejo da adubação nitrogenada para o milho sob palhada de leguminosas em plantio direto em Gurupi, TO. Ciência Rural, Santa Maria, v. 36, n. 4, p. 1100-1105, 2006.

COMPANHIA NACIONAL DE ABASTECIMENTO (Conab). Indicadores da agropecuária: milho. 2007. Disponível em: <http://www.conab.gov.br/conabweb/ index.php?PAG=73\&NSN=399>. Acesso em: dez. 2007.

CRUSCIOL, C. A. C. et al. Persistência de palhada e liberação de nutrientes do nabo forrageiro no plantio direto. Pesquisa Agropecuária Brasileira, Brasília, DF, v. 40, n. 2, p. 161-168, 2005.

DAROLT, M. R.; SKORA NETO, F. Sistema de plantio direto em agricultura orgânica. Revista Plantio Direto, Passo Fundo, v. 70, n. 1, p. 28-30, 2002.

DUARTE JÚNIOR, J. B.; COELHO, F. C. Adubos verdes e seus efeitos no rendimento da cana-de-açúcar no sistema de plantio direto. Bragantia, Campinas, v. 67, n. 3, p. 723 732, 2008.

EMPRESA BRASILEIRA DE PESQUISA AGROPECUÁRIA (Embrapa). Manual de métodos de análise de solo. 2. ed. Rio de Janeiro: CNPS, 1997.

EZEIBEKWE, I. O.; ANYAEGBU, P. O. Performance of maize intercropped with leguminous browse plants at different rates of lime. Journal of Agricultural and Food Science, Owerri, v. 2 n. 1, p. 1-8, 2004.

FARIA, C. M. B; SOARES, J. M.; LEÃO, P. C. S. Adubação verde com leguminosas em videiras no submédio São Francisco. Revista Brasileira de Ciência do Solo, Viçosa, v. 28, n. 3, p. 641-648, 2004.

FONTANETTI, A. et al. Adubação verde na produção orgânica de alface americana e repolho. Horticultura Brasileira, Brasília, DF, v. 24, n. 2, p. 146-150, 2006. 
FOSU, M.; KHÜNE, R.; VLEK, P. L. G. Improving maize yield in the Guinea Savannah zone of Gana with leguminous cover crops and PK fertilization. Journal of Agronomy, Tamale, v. 3 n. 2, p. 115-121, 2004.

GAMA-RODRIGUES, A. C.; GAMA-RODRIGUES, E. F.; BRITO, E. C. Decomposição e liberação de nutrientes de resíduos culturais de plantas de cobertura em Argissolo Vermelho-Amarelo na região noroeste fluminense (RJ). Revista Brasileira de Ciência do Solo, Viçosa, v. 31, n. 4, p. 1421-1428, 2007.

HEINRICHS, R. et al. Características químicas de solo e rendimento de fitomassa de adubos verdes e de grãos de milho, decorrente do cultivo consorciado. Revista Brasileira de Ciência do Solo, Viçosa, v. 29, n. 1, p. 7179, 2005.

MACIEL, A. D. et al. Comportamento do feijoeiro em cultivo consorciado com o milho em sistema de plantio direto. Acta Scientiarum Agronomy, Maringá, v. 26, n. 3, p. 273-278, 2004.

OLIVEIRA, T. K. et al. Plantas de cobertura e seus efeitos sobre o feijoeiro em plantio direto. Pesquisa Agropecuária Brasileira, Brasília, DF, v. 37, n. 8, p. 1079-1087, 2002.

PERIN, A.; GUERRA, J. G. M.; TEIXEIRA, M. G. Cobertura do solo e acumulação de nutrientes pelo amendoim forrageiro. Pesquisa Agropecuária Brasileira, Brasília, DF, v. 38, n. 4, p. 791-796, 2003.

PERIN, A. et al. Desempenho agronômico de milho consorciado com feijão-de-porco em duas épocas de cultivo no sistema orgânico de produção. Ciência e Agrotecnologia, Lavras, v. 31, n. 3, p. 903-908, 2007.

RESENDE, A. S. de et al. Taxa de decomposição de talos e folhas de três leguminosas utilizadas para fins de adubação verde. In: REUNIÃO BRASILEIRA DE MANEJO E CONSERVAÇÃO DO SOLO E DA ÁGUA, 13., 2000, Ilhéus. Anais... Ilhéus: Ceplac/Sociedade Brasileira de Ciência do Solo, 2000. 1 CD-ROM.
SÁ, J. C. de M. Manejo de nitrogênio na cultura de milho no sistema plantio direto. Passo Fundo: Aldeia Norte, 1996.

SILVA, F. A. S. E.; AZEVEDO, C. A. V. A new version of the Assistat - Statistical Assistance Software. In: WORLD CONGRESS ON COMPUTERS IN AGRICULTURE, 4., 2006, Orlando. Anais... Orlando: American Society of Agricultural Engineers, 2006. p. 393-396.

SILVA, F. L. et al. Potencial de restituição de nutrientes através de plantas de cobertura em plantio direto no Tocantins. In: CONGRESSO BRASILEIRO DE CIÊNCIA DO SOLO, 29., 2003, Ribeirão Preto. Anais... Ribeirão Preto: SBCS, 2003. 1 CD-ROM.

SILVA, J. A. A. et al. Reciclagem e incorporação de nutrientes ao solo pelo cultivo intercalar de adubos verdes em pomar de laranjeira-'Pêra'. Revista Brasileira de Fruticultura, Jaboticabal, v. 24, n. 1, p. 225-230, 2002.

TEIXEIRA, C. M. et al. Produção de biomassa e teor de macronutrientes do milheto, feijão-de-porco e guandu anão em cultivo solteiro e consorciado. Ciência e Agrotecnologia, Lavras, v. 29, n. 1, p. 93-99, 2005.

WALKLEY, A.; BLACK, I. A. An examination of the Degtjareff method for determining soil organic matter, and a proposed modification of the chromic acid titration method. Soil Science, Baltimore, v. 37, n. 1, p. 29-38, 1934. 